\title{
Navigating Through the Financial Crisis that may Occur during and after the COVID-19 Pandemic for Gastroenterologists
}

\author{
Dipam A. Patel ${ }^{1} \quad$ Chirag Narendrakumar Shah ${ }^{2}$ \\ ${ }^{1}$ Department of Taxation and Advisory, Kantilal Patel \& Co., \\ Ahmedabad, Gujarat, India \\ 2Department of Gastroenterology, Mission Gastro Hospital, \\ Ahmedabad, Gujarat, India
}

\begin{abstract}
Address for correspondence Chirag Narendrakumar Shah, DM, Department of Gastroenterology, Mission Gastro Hospital, 603, Golden Icon, Besides Qaraar Banquets, Opposite Medilink Hospital, Shyamal to Shivranjani Road, 132 Feet Ring Road, Satellite, Ahmedabad, Gujarat 380015 India, (e-mail: drchirag2606@gmail.com).
\end{abstract}

\begin{abstract}
Introduction Considering the specific set of gastrointestinal endoscopy practitioners, it is witnessed that the number of patients forelective procedures are being deferred by the patients amid various concerns ranging from financial constraint to the fear of infection from the dreaded coronavirus. With Routine endoscopy procedures recommended to be safely postponed, the impact on the practice of Gastrointestinal Endoscopists shall be magnified.

Assessment and Strategy The article discusses impact and remedial actions that may be taken by Gastrointestinal Endoscopists, which classified into:

- Anindependent practitioner

- A consultant

- An employee

The article further touches upon the difficulties that might be envisaged by the Gastrointestinal Endoscopists, and obtain a financial understanding of what could potentially lead to an existential crisis?

Those with cash reserves sit in a pleasant position i.e. they can buy assets at an attractive price, experiment with new ideas, research and development, etc.

It is imperative in these times to understand the uncertainty cast on operations of Gastrointestinal Endoscopists and prepare a response plan for coming out of this eco-

Keywords

- Financial

- COVID-19

- gastroenterologist

- Endoscopist nomic crisis. A roadmap also has been devised which provides a possible outline of a plan that can be implemented for handling the economic crisis.

It is also important to answer these two questions:

1. Who do I want to be during the crisis?

2. Who do I want to be when this is over?
\end{abstract}

The COVID-19 pandemic has been impacting lives globally in more ways than one. The impact of the COVID-19 pandemic is seen in the stringent measures applied by the governments across the world, which impact human lives beyond ordinary.
The Oxford COVID-19 Government Response Tracker, a research project undertaken by the University of Oxford, has ranked 146 nations depending on the stringency of the measures taken by the government (not necessarily representing 
the effectiveness) and developed a stringency index, which places India on the joint first position with 11 other nations for the period starting from March 25, $2020 .{ }^{1}$

In India, the lockdown and its consequent extension have led to a significant drop in demand and consumption in the economy, which shall have its impact far beyond the completion of the crisis. The lockdown has cast some significant issues with various industries, with hospitality and travel being the worst hit. In realistic market conditions, no industry operates in isolation, and hence, impact on one is often marked with cascading effect on the other industries. Considering the larger set of healthcare professionals and the specific set of gastrointestinal endoscopy practitioners, it is witnessed by all that a number of elective procedures, be it surgical or endoscopic, are being deferred by the patients amid various concerns ranging from financial constraint to the fear of infection from the dreaded coronavirus. Avoidance of elective endoscopies is supported by various guidelines. ${ }^{2}$ For gastrointestinal endoscopists, the situation on the economic front is further compounded on account of the warranted joint guidance issued by the Society of Gastrointestinal Endoscopy of India (SGEI), Indian Society of Gastroenterology (ISG), and Indian National Association for Study of the Liver (INASL) for Gastroenterologists and Gastrointestinal Endoscopists which recommends that only emergency and urgent endoscopy procedures may be undertaken until the current threat of COVID-19 lasts. Moreover, routine endoscopy procedures are recommended to be safely postponed. Considering that the routine endoscopy procedures outnumber the combination of the emergency and urgent endoscopy procedures, the impact on the practice of gastrointestinal endoscopists shall increase.

On a macroeconomic front, it is important to ponder as to whether this is the "big collapse." Now and then, certain economic disruptions make us believe that the reaction of the financial markets suggest that it is the next "big collapse." Historically, financial markets have reacted negatively (and maybe sometimes out of proportion) for events like Brexit, trade wars, acts of war/terrorism, and sometimes by events like the Greek default. Every time, the same question lingers as to whether this is the "big collapse."

\section{The Specific Impact on the Healthcare Sector and Gastrointestinal Endoscopists ${ }^{3}$}

The private hospital sector ${ }^{1}$ is estimated to be having annual total revenue of around INR 2.4 lakh crores, and is operating with an EBITDA (earnings before interest, taxes, depreciation, and amortization) margin of around 13\%. EBITDA is the measure of the cash generated by a business, without making payment to the suppliers of capital. - Table 1 denotes summary of financial jargons in this article.

The impact assessment, as gathered from the chain of private hospitals and diagnostic centers, reveals some ground-breaking facts, which are shown in - Table 2.

The impact is not only widespread but also massive in scale on the private healthcare sector, as a whole. Considering the numbers gathered by FICCI, as the directive for the healthcare
Table 1 Summary of the financial jargons used in the ensuing part

\begin{tabular}{|l|l|}
\hline Jargon & Meaning \\
\hline EBITDA & $\begin{array}{l}\text { Earnings before interest, taxes, depreciation, } \\
\text { and amortization. It provides the measure of } \\
\text { free cash that is generated by the business } \\
\text { before reinvestment, i.e., capital expenditure, } \\
\text { payment to suppliers of capital (i.e., debt } \\
\text { capital [interest] or equity capital [dividends } \\
\text { or buyback]), and payment of taxes }\end{array}$ \\
\hline $\begin{array}{l}\text { Interest } \\
\text { coverage ratio }\end{array}$ & $\begin{array}{l}\text { Earnings before interest and taxes divided by } \\
\text { interest payments }\end{array}$ \\
\hline $\begin{array}{l}\text { Cash position in } \\
\text { days }\end{array}$ & $\begin{array}{l}\text { Number of days of cash available to cover } \\
\text { operating cash expenses }\end{array}$ \\
\hline Receivable days & $\begin{array}{l}\text { Number of days after the date of treatment } \\
\text { when payment for treatment provided to a } \\
\text { patient is realized }\end{array}$ \\
\hline
\end{tabular}

Table 2 Impact assessment

\begin{tabular}{|l|l|l|}
\hline \multirow{2}{*}{ Decline } & \multicolumn{2}{|c|}{$\begin{array}{c}\text { Percentage drop when compared with } \\
\text { pre-COVID-19 levels }\end{array}$} \\
\cline { 2 - 3 } & $\begin{array}{l}\text { Private hospitals' } \\
\text { chain }\end{array}$ & $\begin{array}{l}\text { Private diagnostic } \\
\text { chains }\end{array}$ \\
\hline Footfalls/Visits & $70-80 \%$ & $70-80 \%$ \\
\hline Occupancy & $50-60 \%$ & N/A \\
\hline Revenue & $50-60 \%$ & $70-80 \%$ \\
\hline EBITDA (\%) & $60-70 \%$ & $80-90 \%$ \\
\hline
\end{tabular}

Abbreviation: EBITDA, earnings before interest, taxes, depreciation, and amortization.

sector, it can be seen that the days ahead are uncertain and strikingly question survival. With financial indicators such as median interest coverage ratio being as low as two times and median cash position in days as low as 19, it is a lingering question of survival of private healthcare institutions, small and large alike. For private hospitals participating in medical insurance and state-funded schemes, the situation is gloomier considering that the median receivable days is also as high as 45 days.

The figures and the trend mentioned earlier are no different for the gastrointestinal endoscopists. The macroeconomic impact of the coronavirus is such that all specialties and all businesses are engulfed in it. For understanding the impact on gastrointestinal endoscopists, it is essential to categorize the practicing gastrointestinal endoscopists into their specific category depending on their manner of practice. A gastrointestinal endoscopist would generally be functioning in one of the following capacities:

- As an independent practitioner, running his or her setup alongside being associated with some hospital as a visiting consultant.

- As a consultant, exclusively associated with a hospital.

- As an employee, either with an independent practitioner or with a corporate hospital.

The primary reason to categorize gastrointestinal endoscopists for this article is to better understand the specific 
impact for each of these categories of affected gastrointestinal endoscopists, and assess what best recovery methods and techniques can be adopted by them to combat the downside of the COVID-19 pandemic, and mitigate its impact on one's financial position.

\section{The Independent Practitioner}

The independent practitioner has a setup to run. This independent practitioner's category may be working as an individual or a group of individuals running a group practice to manage the setup. This category of the gastrointestinal endoscopists is purported to be the most severely impacted category, owing to their financial commitments of salary, rents, power, and other fixed costs, which shall recur despite their dip in revenue, as well as their remuneration. Hence, this category tends to lose more than the other categories of gastrointestinal endoscopists defined earlier.

\section{The Consultant}

The consultant category of gastrointestinal endoscopists is those practitioners who are associated with setups of individual practitioners or hospitals, as visiting consultants. The peculiarity of this category of consultants is that their cost for the organization in which they are rendering their services is variable-meaning that if there is no revenue generated through them in the setups where they are associated with, there shall be no corresponding payment of professional fees to such consultants by the respective setups where they are associated with. This arrangement is typically known as the "fee-for-service" arrangement, where the consultant gastrointestinal endoscopist is entitled to a fixed percentage/share of the revenue generated from the patient for the setup. In the event of a dip in the revenue collected from the patients by the setup, there shall be a direct dip in the pay-out of professional fee for such gastrointestinal endoscopists engaged as consultants. These are better off than the independent practitioners, as the consultants' financial loss shall be limited to the loss of income, whereas that for the independent practitioner shall be including the loss on account of fixed expenses also. For gastrointestinal endoscopists practicing as consultants, the loss on account of reduced income is absorbed by the setup where they are rendering their services.

\section{The Employee}

The employee category of gastrointestinal endoscopists is those practitioners who are associated with setups of individual practitioners or hospitals, as full-time employees. The economic rewards of their association with such setups or hospitals are generally having a limited upside potential with employers structuring pay packages with a variable component. In times when the inflow of patients is significantly dipped, the downside for this category of gastrointestinal endoscopists can be immediately measured by the loss of the potential upside variable pay component. Additionally, in testing times such as these, where the setups of individual practitioners or hospitals may face an existential crisis, there can also be a situation where layoffs and furloughs may not be very distant. Considering the risk perspective from the three categories of gastrointestinal endoscopists, the employee gastrointestinal endoscopists are least susceptible. That being said, among the employee gastrointestinal endoscopists, those serving as full-time employees at multispecialty hospitals where the contribution of gastrointestinal endoscopy is not significant, may have the highest risk of getting laid-off or furloughed, considering that such hospitals may consider reducing their fixed cost, where the patients of that specialty can be served by visiting consultants, thereby offloading the fixed costs from their operational cost sheet.

\section{What Will Cause an Existential Crisis?}

An understanding of the cash flow position of an organization can be obtained from - Fig. 1 .

Understanding the below basic financial metric of cash flow is essential for appreciating the concern at hand. In normal circumstances, the net cash inflows from operations are a positive figure, and the net cash inflows from investing activities are a negative figure (to propel growth), which are met by raising the deficit by borrowing or getting in more money from the owner. In times of crisis, the wheel turns to reverse where the cash inflows from operations are a negative figure, and there is no availability of debt capital as lenders are wary to give an organization more money as the lenders do not see the capability of the organization to repay the debt. In such a situation, the only source of making good the deficit is by making the cash inflows from investing positive by selling off equipment and other assets, which, in a crisis, fetch only a fire-sale price. If the cash inflows from operations do not turn positive, the ending liquidity position may be negative, which may indicate the fall of an organization.

An existential crisis arises when an organization is unable to service its payables. These payables can be in the form of debt obligation toward lenders or payables for the materials/ services availed by organizations to provide the services. In times of crises like this, there is a steady decline in the inflow of monetary resources into the organization, whereas the outflow for private healthcare service providers (i.e., individual practitioners or hospitals) is largely fixed, viz, salary payments, rent payments, instalments on borrowings, etc.

Though the government has asked lenders to provide a moratorium on instalments for the period up to June 30, 2020 (as per economic stimuli announced on March 24, 2020), the negative net cash flow position from operations of individual practitioners and hospitals is a worrying factor, which may eventually lead for these organizations to call it "quits" if the situation does not improve by the time their cash runs out.

\section{What Can Be Done to Avoid the Ultimate?}

Well, there is no particular remedy that is going to sure-shot make it work for anyone, it is only that certain prudent steps taken along the way can aide survival and sail-through in 


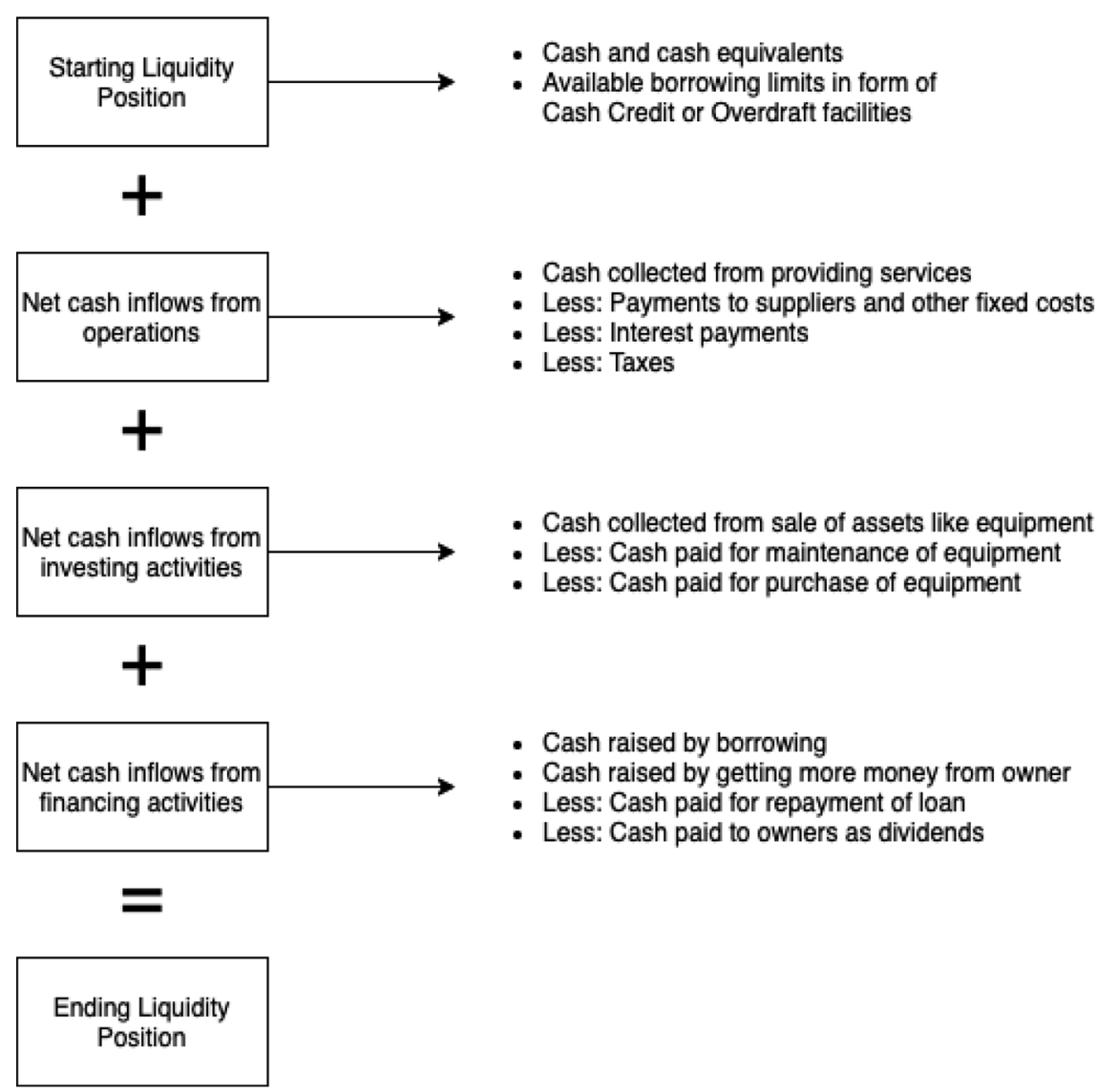

Fig. 1 Understanding the cash flow in an organization.

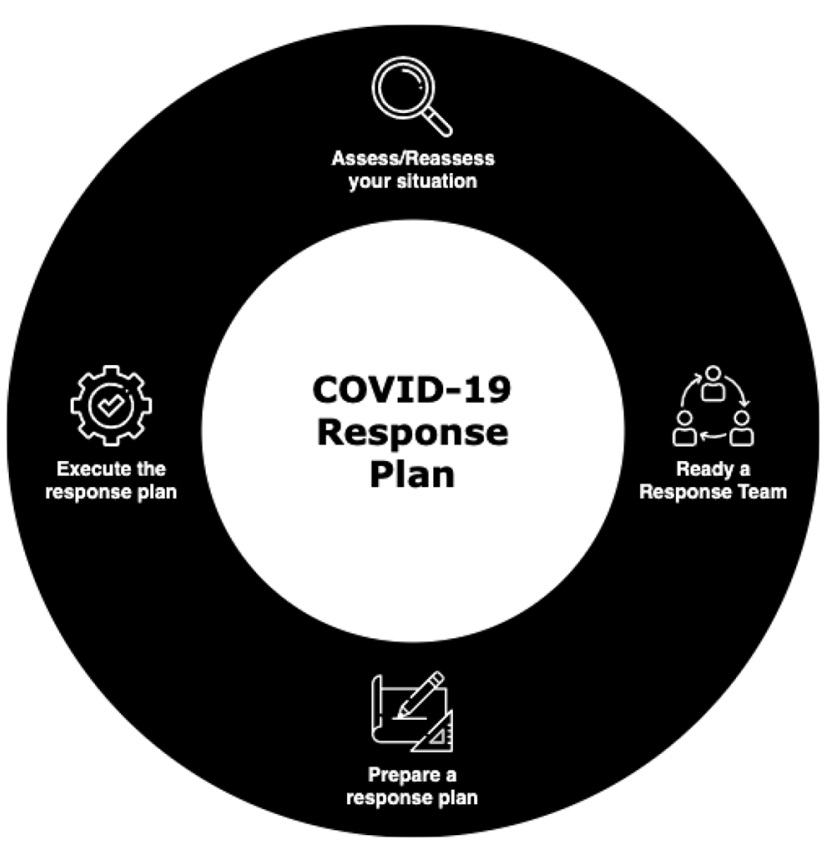

Fig. 2 COVID 19 response plan.

these tough times. Nonetheless, a gastrointestinal endoscopist can adopt to follow the below-mentioned roadmap on a periodic basis (-Fig. 2): the only principle that particularly appears to be giving a guiding light globally is that
“Cash Is King." Cash here means liquidity. A person with the ability to meet its liabilities in time over the next few months or a couple of years would be the one having the upper hand in all transactions over the foreseeable future. Those with cash reserves sit in a pleasant position; i.e., they can buy assets at an attractive price and experiment with new ideas, research, and development, etc. Enhancing cash reserves will be the top priority.

\section{Possible Action Points that Can Form Part of the Response Plan}

A gastrointestinal endoscopist should reassess the situation and tweak the response plan at periodic interval, depending on the changing circumstances. We highlight certain steps that gastrointestinal endoscopists can possibly implement and insert in their response plan to augment their cash resources. No surprises here; the modes of generating cash remain the same.

1. Maximize cash flow: Efforts would have to be maximized for increasing the footfall of patients and the revenue that can be generated from the patients. An increase in the top line (revenue collected from patients) shall directly affect the available cash position with the organization. Efforts would have to be made for setting realistically achievable targets for patients' inflow and revenue generation thereof. 
2. Expense management: The more pragmatic way of preserving cash resources for gastrointestinal endoscopists shall be expense management. The first step is to revisit administration costs including rentals and vendors. For rentals, Force Majeure is a legal clause in most agreements, which means that the promise made under an agreement/contract may not be fulfilled in the unforeseeable circumstances that prevent someone from fulfilling a contract. The Force Majeure clause can be initiated and may be flagged with the counter-party to negotiate on the payments to landlords or vendors. There are certain insurance policies which allow a claim for loss of profit; however, the claim for some healthcare institutions would be weak as healthcare institutions were allowed to function during the lockdown. Incurring capital expenditure and new hiring for growth may best be put on hold till surplus cash reserves are built and things return to normalcy, at least at the pre-COVID-19 levels. With reopening at a relaxed level after the lockdown, the operational requirement would be that for practicing safe distancing and other norms for healthcare institutions, which means additional unvarying cost.

On top of all these expenses, the biggest one that hits gastrointestinal endoscopists' setup is the payment of salary. This one not only has cruciality considering its size in relation to the organization but also is directly seen to be correlated with morality, in the Indian context. Layingoff or furloughing employees is easier said than done in a country like India, especially where the unemployment benefits are not available in a structured manner and not available to all across the board. In such a situation, this aspect of expenses must be approached cautiously. Broadly, such decisions would be market-driven, considering the action taken by peers. Nonetheless, the common consensus for cutting employees' payments appears to be deducting more at the top layer and negligibly at the lowest strata. Again, this needs to be carefully matched to the expected footfalls and revenue for the organization, as, if one could make it through the crisis by paying the employees without cuts, such an organization would have an extremely loyal and reliable workforce when the crisis ends.

3. Government stimuli: In such times of crisis, businesses look up to the government to provide stimuli for the survival of the organizations and save the dent to the economy. While more sops are awaited from the government to combat the economic crisis cast upon us by the COVID19 pandemic, reliance only on the government stimuli might prove fatal. Although more impetus is desired in the form of a reduction in the applicable goods and services tax on medical equipment and supplies, deferment of statutory liabilities to boost liquidity, rebate on power bills, waiver or deferral of license fees, etc., as indicated in the FICCI document referred earlier, it is imperative for organizations to prepare a COVID-19 response plan for themselves. This response plan must have to be prepared for each of the three categories of gastrointestinal endoscopists discussed earlier.

\section{Conclusion}

As Charles Kettering has put it, "A problem well-stated is half-solved." It is imperative in these times to understand the uncertainty cast on operations of gastrointestinal endoscopists and prepare a response plan for coming out of this economic crisis. You may not have to worry to survive if your organization has enough cash resources to survive for another full year of fixed costs; nonetheless, even such organizations should use their cash judiciously, as, in uncertain times, there is no definition of normal. Another important decision that might be required to be taken by organizations would be revolving around the actions that are necessary to be taken at the appropriate time. Delayed decisions may have allowed more water to pass resulting in potentially irreversible damage. Setting your goals, priorities, and values in place will allow you to steer efficiently through the situation.

Conflict of Interest

None declared.

\section{References}

1 https://www.bsg.ox.ac.uk/research/research-projects/coronavirus-government-response-tracker. Accessed April 27, 2020

2 Chiu PWY, Ng SC, Inoue H, et al. Practice of endoscopy during COVID-19 pandemic: position statements of the Asian Pacific Society for Digestive Endoscopy (APSDE-COVID statements) Gut 2020;doi10.1136/gutjnl-2020-321185[ Epub ahead of print]

3 "COVID-19 - Impact assessment for private healthcare sector and key recommendations on financial measures required for the sector." available at: http://ficci.in/spdocument/23205/ Healthcare-Impact-Recommendations.pdf. Accessed April 27, 2020 